\title{
Notes on the Editors and Contributors
}

Martin Abraham is Professor of Sociology and Empirical Social Research at the School of Business, Economics and Society at the Friedrich Alexander University Erlangen-Nürnberg, Germany. His research focuses on labor markets, organizations, economic exchange and households.

Ozan Aksoy is Lecturer (Assistant Professor) in Social Science at University College London, United Kingdom. His main research interests are cooperative behavior in modern societies and the political sociology of religion.

Marcel van Assen is Professor of Mathematical Sociology (special appointment by James Coleman Association) at the Department of Sociology/ICS, Utrecht University and Associate Professor at the Department of Methodology and Statistics and the Meta-Research Center, Tilburg University, the Netherlands. His research interests include mathematical sociology, social dilemmas, social networks, social science methodology, and meta-research.

Davide Barrera is Associate Professor at the Department of Culture, Politics and Society of the University of Turin and research affiliate at Collegio Carlo Alberto, Italy. His research interests are cooperation problems, behavioral game theory, experimental research, organizations, group processes, social networks, and actor-based social theory.

Michal Bojanowski is an Assistant Professor at the Chair of Quantitative Methods and Information Technology, Kozminski University, Poland. His research interests revolve around social networks and mathematical/computational social science as tools for understanding conflict and cooperation.

Vincent Buskens is Professor of Sociology at the Department of Sociology/ICS, Utrecht University, the Netherlands. His research interests include sociological theory, game theory, mathematical sociology, experimental sociology, social dilemmas, social networks, and institutions.

Rense Corten is Associate Professor at the Department of Sociology/ICS, Utrecht University, the Netherlands. His research interests include cooperation, trust, and (the dynamics of social networks, with empirical applications including adolescent networks, social media, the sharing economy, online criminal networks, and laboratory experiments.

Andreas Diekmann is Professor em. of Sociology at the ETH Zurich, Switzerland (2003 - 2016) and a Senior Professor at the University of Leipzig, Germany (since 2018). His research interests focus on theories of social cooperation, experimental game theory, environmental and population sociology, and methods of empirical research.

Jacob Dijkstra is Associate Professor of Sociology at the Department of Sociology/ICS at the University of Groningen, the Netherlands. His research interests include experimental methods, game theory, social networks, and formal theory.

Christoph Engel is Director at the Max Planck Institute for Research on Collective Goods in Bonn, Germany, and Professor of Law at the Universities of Bonn and Rotterdam. His work centers on the behavioral analysis of legal intervention, mostly using experimental methods. 
Hartmut Esser is Professor Emeritus of Sociology and Philosophy of Science at the University of Mannheim, Germany. His research interests include sociological theory, methodology of the social sciences, theories of action, migration, integration and ethnic conflicts, marital relations, and (currently) educational systems and educational inequality.

Andreas Flache is Professor of Sociology at the Department of Sociology/ICS at the University of Groningen, the Netherlands. His research focuses on computational modeling, social complexity, opinion dynamics, cooperation, experimental research, and social networks.

Henk Flap is Professor Emeritus of Sociology at the Department of Sociology/ICS at Utrecht University, the Netherlands. His research interests are social networks, the development of a social capital theory and testing it in various institutional contexts. Another of his research interests is the persecution of Jews in World War II.

Vincenz Frey is postdoctoral researcher at the Department of Sociology/ICS, University of Groningen, the Netherlands. His fields of interest include cooperation, trust, (the formation of) social networks, and processes of social influence.

Thomas Gautschi is Professor of Sociological Methodology at the University of Mannheim, Germany. His research and teaching interests include game theory, network analysis, model building, economic sociology, social science methodology and statistics, and experimental methods.

Francesca Giardini is Assistant Professor at the Department of Sociology/ICS, University of Groningen, the Netherlands. Her research interests include the mechanisms of social sustainability, especially the role of reputation and gossip on cooperation in groups, communities and organizations, inter-organizational networks, opinion dynamics and agent-based modeling.

Rainer Hegselmann is Professor of Philosophy at the Frankfurt School of Finance \& Management, Germany. His research interests include modelling and simulation of social processes, opinion dynamics, social epistemology, philosophy of science, moral philosophy and the history of analytical philosophy.

Frank Kalter is Professor of Sociology at the University of Mannheim and Director of the German Center for Integration and Migration Research (DeZIM-Institute), Berlin, Germany. His major research interests include migration, integration, interethnic relations and the formal modeling of social processes.

Ferry Koster is Associate Professor at the Department of Public Administration and Sociology, Erasmus University Rotterdam, The Netherlands. His research interests include the sociology of labor market, organizations and institutions, and focuses on topics such as innovation, employability and social risks.

Siegwart Lindenberg is Professor of Cognitive Sociology at the Department of Sociology/ICS, University of Groningen, and the Department of Social Psychology, Tilburg University, the Netherlands. His interests lie in the development, testing and application of theories of social rationality that deal with the influence of the social environment on social need fulfillment, norms, cooperative behavior and self-regulation. 
Tanja van der Lippe is Professor of Sociology the Department of Sociology/ICS, Utrecht University, the Netherlands. Her research interests include the work family interface, time use and time pressure, and the position of men and women on the labor market in a comparative way.

Kerstin Lorek is currently Representative for the School Board at the School of Business, Economics and Society, Friedrich-Alexander University Erlangen-Nürnberg, Germany.

Axel Ockenfels is Professor of Economics at the University of Cologne, Germany, and Speaker of the University's Excellence Center for Social and Economic Behavior. His research interests include market design and behavioral economics.

Karl-Dieter Opp is Professor Emeritus at the University of Leipzig, Germany, and Affiliate Professor at the University of Washington (Seattle), United States. His fields of interest are social theory, political participation, social norms and institutions, and the philosophy of the social sciences.

Bernhard Prosch was Professor of Sociology at the Friedrich-Alexander University ErlangenNürnberg, Germany. His main research areas were economic sociology, game theory, innovative methods of university teaching. He sadly passed away on September 23, 2015.

Arnout van de Rijt is Professor of Sociology at the European University Institute, Italy, and Utrecht University/ICS, the Netherlands. His research interests include computational social science, social networks, mathematical sociology, stratification, collective action, the sociology of science, the energy transition, immigrant integration, political polarization, and the spread of misinformation.

Anne Roeters is a senior researcher at the Netherlands Institute for Social Research (Sociaal en Cultureel Planbureau), The Hague, the Netherlands. Her research interests include time use, family sociology and the interface between work and family life.

Gerrit Rooks is Assistant Professor of Human Technology Interaction at Eindhoven University of Technology. The Netherlands. His main research interests are in humans embedded in social context, networks of relations and institutions, and how social embeddedness affects innovation and performance.

Stephanie Rosenkranz is Professor of Microeconomics at the Utrecht School of Economics, the Netherlands. Her research interests are in strategic framing and endogenous preferences, sustainable decision making, and social and economic networks.

Vera de Rover (Wiedemann) is currently Consumer and Sensory Insights Expert and Quality Manager at Essensor B.V. Essensor is a sensory market research company, specialized in supporting the food and non-food sectors in optimizing and selling products using market research that employs the human senses of smell, taste, vision, hearing and touch.

Esther de Ruijter is managing partner at Arbeid Opleidingen Consult, Giessenburg, the Netherlands. Her research interests include education and the labor market, household decision-making, rational choice theory and trust.

Chris Snijders is Professor of the Sociology of Technology and Innovation at the HumanTechnology Interaction group of Eindhoven University of Technology, the Netherlands. His research 
interests include human and computer-based decision making, online behavior and measurement, human-data interaction, and behavioral research methods.

Tom Snijders is Emeritus Professor of Statistics and Methodology at the Universities of Groningen, the Netherlands and Oxford, United Kingdom and Emeritus Fellow of Nuffield College (Oxford). He works at the interface of sociology and statistical modeling, with a focus on dynamics of social networks and multilevel modeling.

Frits Tazelaar was Professor of Sociology at the Department of Sociology/ICS, Utrecht University, the Netherlands. His research interests included relations within and between organizations. He sadly passed away on March 9, 2018.

Wout Ultee is Emeritus Professor of Sociology at the Department of Sociology/ICS, Radboud University Nijmegen, the Netherlands. His research interests include educational heterogamy, religious assortative marriage, coupled careers, thinking in analogies versus rational choices, and problem selection in sociology.

Beate Volker is Professor of Human Geography at Utrecht University, the Netherlands. Her research interests include social capital theory, the development of social networks and relationships through time, and the conditions for social cohesion and community in neighborhoods.

Thomas Voss is Professor of Sociology at the University of Leipzig, Germany. His research interests include rational choice and game theory, philosophy of social science, and economic sociology.

Fabian Winter is Head of Research Group Mechanisms of Normative Change at the Max Planck Institute for Research on Collective Goods, Bonn, Germany. His research interests include social norms, social dilemmas, and experimental sociology.

Rafael Wittek is Professor of Sociology at the Department of Sociology/ICS, University of Groningen, the Netherlands, and Scientific Director of the transdisciplinary research and training program Sustainable Cooperation (SCOOP). His research interests include sustainable cooperation and societal resilience, economic and organizational sociology, and social network analysis. 